\title{
Tissue Engineering and Regenerative Medicine
}

\section{Towards reconstruction of epithelialized cartilages from autologous adipose tissue-derived stem cells}

\begin{tabular}{|c|c|}
\hline Journal: & Journal of Tissue Engineering and Regenerative Medicine \\
\hline Manuscript ID & TERM-15-0547.R1 \\
\hline Wiley - Manuscript type: & Research Article \\
\hline Date Submitted by the Author: & $\mathrm{n} / \mathrm{a}$ \\
\hline Complete List of Authors: & $\begin{array}{l}\text { New, Sophie ; UCL Institute of Child Health, University College London, } \\
\text { Stem Cells and Regenerative Medicine Section } \\
\text { Ibrahim, Amel; UCL Institute of Child Health, University College London, } \\
\text { Stem Cells and Regenerative Medicine Section } \\
\text { Guasti, Leonardo ; Barts and the London, Queen Mary University of } \\
\text { London, Centre for Endocrinology, William Harvey Research Institute } \\
\text { Zucchelli, Eleonora ; UCL Institute of Child Health, University College } \\
\text { London, Stem Cells and Regenerative Medicine Section } \\
\text { Birchall, Prof; University College London, UCL Ear Institute, Royal National } \\
\text { Throat, Nose and Ear Hospita } \\
\text { Bulstrode, Neil; Great Ormond Street Hospital NHS Trust, Department of } \\
\text { Plastic Surgery } \\
\text { Seifalian, Alexander; University College London, Centre for Nanotechnology } \\
\text { and Regenerative Medicine, Division of Surgery and Interventional Science } \\
\text { Feretti, Patrizia; UCL Institute of Child Health, University College London, } \\
\text { Stem Cells and Regenerative Medicine Section }\end{array}$ \\
\hline Keywords: & $\begin{array}{l}\text { adipose tissue derived stem cell (ADSC), cartilage, differentiation, } \\
\text { epithelium, human, nanomaterial }\end{array}$ \\
\hline
\end{tabular}

\section{SCHOLARONE \\ Manuscripts}


Sophie E. P. New, $\mathrm{PhD}^{\mathrm{a}}$, Amel Ibrahim, MD ${ }^{\mathrm{a}}$, Leonardo Guasti, $\mathrm{PhD}^{\mathrm{b}}$, Eleonora Zucchelli, MSc ${ }^{\text {a }}$, Martin Birchall, MD, FRCS, FMed Sci ${ }^{\text {c }}$, Neil W. Bulstrode, MD ${ }^{\text {d }}$, Alexander M. Seifalian, $\mathrm{PhD}^{\mathrm{e}}$, Patrizia Ferretti, $\mathrm{PhD}^{\mathrm{a}, *}$

${ }^{a}$ Developmental Biology Unit, Institute of Child Health, University College London (UCL), London, United Kingdom

${ }^{\mathrm{b}}$ Centre for Endocrinology, William Harvey Research Institute, Barts and the London, Queen Mary University of London, London, United Kingdom

${ }^{c}$ UCL Ear Institute, Royal National Throat, Nose and Ear Hospital, UCL, London, United Kingdom

${ }^{\mathrm{d}}$ Department of Plastic Surgery, Great Ormond Street Hospital NHS Trust, London, United Kingdom

${ }^{\mathrm{e}}$ Centre for Nanotechnology and Regenerative Medicine, Division of Surgery and Interventional Science, UCL, London, United Kingdom

Running title: Epithelialized cartilage from paediatric adipose tissue-derive stem cells

Keywords: adipose tissue derived stem cell (ADSC), cartilage, differentiation,

epithelium, human, nanomaterial

Corresponding Author:

Patrizia Ferretti

Stem Cells and Regenerative Medicine Section

UCL Institute of Child Health

30 Guilford Street

London WC1N 1EH

E-mail: p.ferretti@ucl.ac.uk

Tel: (+44) 020-7905 2372 (direct line)

(+44) $0207905-2715$ or -2641 (section administrator)

Fax: (+44) 02079052953 


\begin{abstract}
Deformities of the upper airways, including those of the nose and throat, are typically corrected by reconstructive surgery. The use of autologous somatic stem cells for repair of defects could improve quality and outcomes of such operations. We explored the ability of paediatric adipose-derived stem cells (pADSCs), a readily available source of autologous stem cells, to generate a cartilage construct with a functional epithelium. pADSCs seeded on the biodegradable nanocomposite polymer, POSS-PCL, proliferated and differentiated towards mesenchymal lineages. ADSCs infiltrated 3D POSS-PCL nanoscaffold and chondroid matrix was observed throughout chondrogenically-induced samples. In ovo chorioallantoic membrane-grafted ADSCnanoscaffold composites were enwrapped by host vessels indicating good compatibility in an in vivo system. Furthermore, pADSCs could be induced to transdifferentiate towards barrier-forming epithelial-like cells. By combining differentiation protocols, we were able to generate epithelial cell lined chondrogenic micromasses from the same pADSC line. This proof-of-concept study is the first to our knowledge to demonstrate that individual pADSC lines can differentiate towards two different germlines and be successfully co-cultured. This has important implications for bioengineering of paediatric airways and further confirms the plastic nature of ADSCs.
\end{abstract}




\section{Introduction}

External ear and upper airway abnormalities, such as those affecting the nose or the trachea, maybe congenital or arise due to neoplasia, trauma, infection or inflammation. As spontaneous regeneration of cartilage and bone in the craniofacial region is limited, the current "gold standard" procedure for these facial reconstructions involves use of autologous costal cartilage (Fattah et al., 2010, Firmin, 2010, Fischer et al., 2014). While this surgical intervention can significantly improve paediatric patients' appearance and function, hence their quality of life, it involves harvesting the rib cartilage, an invasive surgical procedure. Crucially, this creates a permanent defect at the donor site where the costal cartilage is removed, which itself often requires some form of defect repair (Fattah et al., 2010). Repair of the upper airways does not only require cartilage reconstruction, as in the case of the ear, but ideally also a functional epithelial lining to provide a barrier against inflammatory agents (Ganesan et al., 2013). To date, methods to form a fully functional epithelium from a readily accessible, abundant and easily expandable autologous cell source have been lacking. We propose that autologous stem cells for the repair of cartilage tissue defects may improve the outcomes of paediatric surgery of the ear and upper airways thereby reducing the need for repeated invasive operative interventions.

Adipose tissue-derived stem cells (ADSCs) are an attractive cell source due in part to their relative ease of isolation using routine liposuction procedures. Autologous adipose cells may be retrieved and used therapeutically in the same operative procedure bypassing the needs for immunosuppression and storage and cutting costs. Many studies have investigated the potential therapeutic use of induced pluripotent stem cells (iPSCs). 
iPSCs have been shown to differentiate towards cells of different germ layers, but concerns about tumorigenicity and the expense of reprogramming remain (Csobonyeiova et al., 2015, Zhang and Xu, 2012, Kimbrel and Lanza, 2015). By contrast, ADSCs have a high safety record and are inexpensive to retrieve (Gimble et al., 2010).

ADSCs exhibit similar characteristics to the widely studied bone marrowderived mesenchymal stem cells (MSCs); however ADSCs have the added benefit that a greater quantity of stromal stem cells can be isolated from adipose tissue (Colazzo et al., 2010). In addition, our past studies have established the plastic nature of pediatric ADSCs, pADSCs (Guasti et al., 2012, New et al., 2015). Their potential to differentiate towards a number of cell types from different germlines (Heneidi et al., 2013) offers a wide range of potential therapeutic applications. Previously, the ability of mesenchymal stem cells to transdifferentiate towards cells originating from endodermal and mesodermal germ layers has been met with some scepticism. Brzoska et al., were the first to show the transdifferentiation of ADSCs towards an epithelial cell phenotype in vitro, with the use of retinoic acid (Baer et al., 2011, Brzoska et al., 2005). Since then, in vivo studies with locally injected ADSCs, genetically modified labelled for easy detection and tracking, have suggested that these cells undergo transdifferentiation towards keratinocytes, contributing to wound healing (Morissette Martin et al., 2015, Shingyochi et al., 2015). Despite this, a functional epithelium has yet to be differentiated/ generated from ADSCs.

Cells grown within a 3-dimensional (3D) environment adopt a morphology that is more representative of that observed in vivo (Cukierman et al., 2001), supporting the belief that the cells are experiencing a more physiological environment in such cultures. 
The scaffold material in which the cells are seeded needs to act as a framework to keep the cell population in the correct spatial arrangement. It also needs to provide mechanical support until the cells have synthesised the appropriate levels of organised and structurally stable extracellular matrix (ECM), thus creating their "niche". Thus, the use of a rigid synthetic polymeric scaffold is attractive for bioengineering of the upper airways, since constructs need to be structurally rigid upon implantation to prevent collapse during inspiration. Our group previously showed the ability of pADSCs to undergo chondrogenic differentiation when seeded in POSS-PCU nanoscaffold (Guasti et al., 2014), a non-biodegradable scaffold, which has already been used for the first-inman synthetic tracheobronchial transplantation (Jungebluth et al., 2011). However, for tissue engineering applications in paediatric patients a biodegradable scaffold, which has the potential to degrade over time, would be more beneficial. Hypothetically, the scaffold would degrade over time, leaving in its place only the conditioned cells and cell-generated matrix. A dynamic structure that grows and remodels may remove the need for repeated surgical interventions as the child grows. Therefore, we explored the feasibility of pADSCs and a biodegradable nanocomposite polymer, polyhedral oligomeric silsesquioxane poly( $\epsilon$-caprolactone-urea) urea urethane (POSS-PCL) to act as the basis for bioengineered upper airway repair constructs.

\section{Materials and Methods}

\subsection{Materials}

All chemicals and reagents were purchased from Sigma-Aldrich, unless otherwise stated. 


\subsection{POSS-PCL Polymer Synthesis and Scaffold Preparation}

Two forms of POSS-PCL were fabricated, non-porous cast ("2-dimensional (2D)") and coagulated porous scaffold (“3D”), for this study. The nanocomposite polymer solutions were prepared as described previously (Gupta et al., 2009). 3D POSS-PCL nanocomposite scaffolds, comprising $80 \%$ polycaprolactone and $20 \%$ polycarbonate with a urea hard segment, were fabricated by combining porogen leaching with coagulation techniques. Porogen particles, sodium bicarbonate $\left(\mathrm{NaHCO}_{3}\right)$, were sieved to obtain particles between $50-150 \mu \mathrm{m}$ in size and dissolved in an 18 weight $\%$ solution of POSS-PCL in DMAc containing Tween 20 surfactant. The slurry of $\mathrm{NaHCO}_{3} / \mathrm{POSS}-\mathrm{PCL}$ was produced by dispersing and degassing of the mixture using a Thinky AER 250 mixer (Intertonics, Kidlington, UK). The slurry mixture was poured onto a mould, with a desired thickness of $1 \mathrm{~mm}$, and immersed in deionised water for 24 hours - resulting in the formation of a coagulated porous $3 \mathrm{D}$ scaffold. To ensure complete removal of $\mathrm{NaHCO}_{3}$ and DMAc the scaffold was thoroughly washed for 72 hours in pure deionised water with frequent water changes to ensure the complete removal of $\mathrm{NaHCO}_{3}$ and DMAc. The resultant 3D nanoscaffolds have $87 \%$ porosity and an average pore size of $15 \mu \mathrm{m}$ as previously reported. The non-porous $2 \mathrm{D}$ nanoscaffold was produced by omitting the addition of $\mathrm{NaHCO}_{3}$ and cast onto a metal sheet in the oven for at $50{ }^{\circ} \mathrm{C}$ for 20 hours followed by serial washes in deionized water for 72 hours. 2D and 3D scaffolds were then cut to $15 \mathrm{~mm}$ discs with a metal die and sterilized by autoclaving.

\subsection{Adipose Tissue-Derived Stem Cells (ADSCs)}

Lipoaspirates were obtained in a minimally invasive manner using needle aspiration of the abdominal fat through a small stab incision to the abdominal skin (Strong et al., 
2015) from consented paediatric patients under ethical approval from the Camden and Islington Community Local Research Ethics Committee (London, UK). Paediatric adipose tissue-derived stem cells (pADSCs) were isolated from the lipoaspirates as previously described (Guasti et al., 2012). In brief, the fat was washed extensively with phosphate-buffered saline (PBS, PAA Laboratories) and digested with $0.05 \%$ trypsin $/ 1 \mathrm{mM}$ EDTA (Life Technologies) in a $37^{\circ} \mathrm{C}$ shacking incubator for $1 \mathrm{hr}$. Following centrifugation to remove floating mature adipocytes, cell pellets were incubated with red blood cell lysis buffer (Roche) and centrifuged again to obtain 'stromal vascular fraction' containing ASDCs. Chick ADSCs were isolated from fat deposit explants from GFP-chick embryos at E18.5 following the same protocol (Guasti et al., 2012, McGrew et al., 2004). Both human and chick ADSCs were cultured in high glucose Dulbecco's modified Eagle's medium (DMEM) containing GlutaMAX ${ }^{\mathrm{TM}}$ and supplemented with $10 \%$ embryonic stem cellqualified foetal bovine serum (ES-FBS) and 1\% penicillin/streptomycin (all Life Technologies), this media will be referred to as "complete medium" in this manuscript.

\subsection{Assessment of Cell Proliferation and Viability}

The proliferative capability and viability of the pADSCs were assessed as previously described (Guasti et al., 2014). The same amount of cells ( $10^{4}$ cells/ sample) was seeded on either non-porous POSS-PCL 2D disks or plastic, and 24 hours later they were assessed for either cell viability or proliferation. Cell viability was assessed using propidium iodide (PI, Invitrogen, $2 \mu \mathrm{g} / \mathrm{ml})$ and Hoechst $33258(5 \mu \mathrm{g} / \mathrm{ml})$ live staining. The dyes were added directly to the cell culture medium and samples were incubated at $37{ }^{\circ} \mathrm{C}$ for 2 hours prior to imaging. Cell proliferation was assessed using bromodeoxyuridine $(\mathrm{BrdU})$ incorporation. After 16 hours incubation in cell culture medium spiked with BrdU $(1 \mu \mathrm{M})$, the samples were fixed using ice cold $70 \%$ ethanol, 
the DNA denatured with $2 \mathrm{M} \mathrm{HCl}$ at $37{ }^{\circ} \mathrm{C}$ for 30 minutes and then samples were neutralized with $0.1 \mathrm{M}$ borate buffer $(\mathrm{pH} 9.0)$ for 2-3 minutes. After washing in PBS and an incubation in blocking solution composed of $2 \%$ goat serum in PBS with $0.1 \%$ Triton $\mathrm{X}-100$, BrdU was detected using a monoclonal rat primary antibody (Serotec OBT0030, dilution 1:100 in blocking solution) and a secondary goat anti-rat Alexa594 (Life Technologies, dilution 1:400). The nuclei were labelled using Hoechst 33258 (5 $\mu \mathrm{g} / \mathrm{ml})$. For both analyses samples were imaged with an Olympus $1 \times 71$ inverted microscope with a Hamamatsu C10600 ORCA-R ${ }^{2}$ digital camera using HCImage software. The number of PI or BrdU positive cells were counted in at least 5 representative fields/ sample and expressed as a percentage of the total number of cells. Experiments were performed at least in triplicates with cells obtained from three patients.

\subsection{ADSC Differentiation}

ADSC differentiation along the adipogenic, chondrogenic and osteogenic lineages was induced as previously described (Guasti et al., 2012, New et al., 2015). Epithelial differentiation was induced in confluent pADSCs, seeded on plastic with or

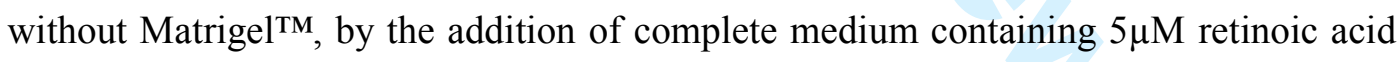
(Brzoska et al., 2005) for 3 weeks unless otherwise stated. The mRNA expression was obtained from experiments performed without the Matrigel ${ }^{\mathrm{TM}}$ coating.

In the POSS-PCL experiments, ADSCs, from chick or paediatric patients, were either seeded onto non-porous $100 \mu \mathrm{m}$ thick discs of POSS-PCL (2D POSS-PCL) or porous $1 \mathrm{~mm}$ thick pieces of POSS-PCL (3D POSS-PCL). Those seeded on the 2D POSS-PCL discs were differentiated for 3 weeks towards the adipogenic, chondrogenic and osteogenic lineages, using previously described differentiation protocols (Guasti et 
al., 2012). Those ADSCs seeded onto the 3D POSS-PCL were allowed to proliferate and infiltrate the scaffold for 7 days prior to being chondrogenically differentiated for 4 weeks. Epithelial differentiation of pADSCs seeded on POSS-PCL was carried out as on plastic. In the experiments establishing the effect of POSS-PCL on the epithelial differentiation of pADSCs, Matrigel ${ }^{\mathrm{TM}}$ was not used. Cells were differentiated for 3 weeks. Each differentiation experiment was performed with cells from three different patients, with the exception of the data shown in Figure $3 \mathrm{C}$ in which one cell line was used in triplicate.

\subsection{Trans-Epithelial Electrical Resistance (TEER) Measurement}

pADSCs were plated on $1 \mu \mathrm{m}$ transwell® polyester membranes (Millipore) coated with Matrigel ${ }^{\mathrm{TM}}$ (BD Biosciences). Once confluent the media was changed to epithelial induction media. The trans-epithelial electrical resistance was measured at various time-points (1-, 2- and 3-weeks control and epithelial differentiated) using an epithelial voltmeter fitted with chopstick electrodes (EVOM, World Precision Instruments Ltd.). The experiment was performed in triplicate with cells from three different patients.

\subsection{Generation of Epithelial-Chondrogenic Micromasses}

Micromasses were formed from $10^{5}$ pADSCs in complete media. After micromass formation the media was replaced by chondrogenic media for 4 weeks. Cells from the same paediatric ADSC line were pre-stimulated with epithelial differentiation

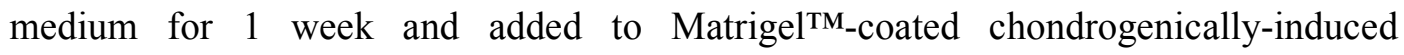
micromasses, creating epith-chondro micromass samples. After 2 more weeks of epithelial induction (6 weeks differentiation in total) the micromasses were harvested 
for analysis by immunofluorescence. Experiments were performed in two different patient lines.

\subsection{Histology, Immunohistochemistry and Immunofluorescence}

All samples were fixed in $4 \%$ paraformaldehyde and washed in phosphatebuffered saline (PBS) prior to processing. After being fixed, ADSC-seeded POSS-PCL nanoscaffolds were embedded in OCT (Thermo Fisher Scientific) and sectioned for histological and immunohistochemical evaluation. Free-floating sections of POSS-PCL were stained with $1 \%$ Alcian Blue in $\mathrm{HCl}$ to analyse chondroid matrix content. For immunohistochemical analysis, POSS-PCL sections were incubated in blocking solution (10\% foetal bovine serum (FBS), 3\% bovine albumin serum (BSA) and $0.2 \%$ Triton-X100) and incubated in the primary mouse antibody to chicken monocytes and macrophages (Abcam, clone KUL01, 1:100 dilution in blocking solution) for 1 hour at room temperature (RT). After washing with PBS, sections were incubated in biotinylated goat anti-mouse (Dako, 1:400 dilution) for 1 hour at RT. Vectorstain Avidin-Biotin Complex kit (Vector Laboratories) was used in conjunction with 3, 3'diaminobenzidine to detect the target antigen signal, a dark brown reaction product. Cell nuclei were counterstained with haematoxylin and images were acquired with an Axiovert 135 (Zeiss) with a ProgRes C14 digital camera using OpenLab software (PerkinElmer Life).

For the immunofluorescence analysis of POSS-PCL, monolayer cells and micromasses, fixed samples were incubated in blocking solution and then incubated in primary antibody for 1 hour at RT (overnight at $4^{\circ} \mathrm{C}$ for $3 \mathrm{D}$ structures). The following primary antibodies were used: rabbit anti-aggrecan (Santa Cruz, sc-25674, 1:100 dilution in blocking solution), rabbit anti-collagen II (Abcam, 1:200 dilution), rabbit 
anti-ZO-1 (Life Technologies, 1:100 dilution) and mouse anti-CK-18 (Millipore, 1:200 dilution). After washing in PBS, samples were incubated for 1 hour at RT (5 hours at $4^{\circ} \mathrm{C}$ for $3 \mathrm{D}$ structures) in secondary antibodies, Alexa Fluor 594 donkey anti-rabbit or Alexa Fluor 488 donkey anti-mouse (both Invitrogen, 1:400 dilution), and Hoechst 33258. Some micromasses were incubated with fluorescein phalloidin for 5 hours at $4^{\circ} \mathrm{C}$ (Thermo Fisher Scientific, 1:400 dilution). Images were either obtained with a Zeiss LSM710 confocal using Zen software or an Olympus $1 \times 71$ inverted microscope equipped with a Hamamatsu C10600 ORCA-R2 digital camera using HCImage software.

\subsection{Reverse Transcription-Polymerase Chain Reaction and Quantitative Real-Time} Polymerase Chain Reaction

RNA was extracted from cells and tissue using Tri-Reagent (Life Technologies) according to the manufacturer's protocol. RNA was retro-transcribed with Moloney murine leukaemia virus reverse transcriptase (Promega) and mRNA was quantified by real-time quantitative polymerase chain reaction with the 7500 -sequence detection system (Applied Biosysytems) and the Quantitect SYBR Green PCR kit (Qiagen) following the manufacturer's instructions. Primers for the epithelial marker, cytokeratin-18 (CK18) were: Forward (5'-3') CACAGTCTGCTGAGGTTGGA and Reverse (5'-3') CAAGCTGGCCTTCAGATTTC. Gene expression data were normalized using GAPDH housekeeping gene as a reference. Primers for GAPDH were: Forward (5'-3') TGATGACATCAAGAAGGTGGTGAAG and Reverse (5'-3') TCCTTGGAGGCCATGTGGGCCAT. Fold changes were calculated taking untreated ADSCs (controls) as a reference. 


\subsection{Chorioallantoic Membrane (CAM) Grafting}

Procedures were carried out under the Animals Scientific Procedures Act 1986 and as previously described in (Guasti et al., 2014). Briefly, fertilized Brown Leghorn eggs (Needle Farm, Cambridge, UK) were incubated at $38^{\circ} \mathrm{C}$ in a humidified incubator. After 3 days of incubation, the eggs were windowed. After 7 days, the CAM was slightly scratched near bifurcations in the blood vessels to induce angiogenesis. Small pieces (approximately $1 \times 2 \mathrm{~mm}$ ) of POSS-PCL, unseeded and seeded with ADSC, were placed on the scratched region of the CAM. After an additional 8 days of incubation, the grafts were observed and imaged prior to processing for immunohistochemistry.

\subsection{Statistical Analysis}

Data are presented as mean $\pm \mathrm{SEM}$. The statistical analysis was performed using GraphPad Prism version 5.00 for Windows. Statistical significance was evaluated by Student's t-test or ANOVA followed by a Bonferroni post-test. A $\mathrm{p}$ value equal to or less than 0.05 was considered as statistically significant.

\section{Results}

\subsection{Transdifferentiation of pADSCs towards an Epithelial-like Cell}

In order to establish whether pADSCs have potential for engineering an epithelium-lined cartilage, it was necessary to first assess the potential of ADSCs to generate epithelial-like cells. Matrigel ${ }^{\mathrm{TM}}$ substrate was found to enhance the epithelial differentiation of pADSCs (Suppl. Fig. 1) and was used to coat the cell culture vessels for optimum results. Expression of specific epithelial differentiation markers was determined by immunofluorescence and RT-qPCR (Fig. 1A-D). Cytokeratin-18 (CK- 
18), a columnar epithelial marker, was significantly up-regulated on both a protein and gene level after 3 weeks of epithelial induction in a retinoic acid-supplemented medium. Whereas no keratin staining was detected in control cells grown on plastic, that also upregulated keratin expression in response to epithelial induction with retinoic acid (Suppl. Fig. 2 and 3), control cells on laminin were very occasionally found to contain a few positive cells in confluent regions. The tight-junction marker, zonula occludens-1 (ZO-1), was expressed in the cytoplasm of control pADSCs and translocated from the cytoplasm to the cell-cell contacts after epithelial induction indicating formation of tight junctions. In order to assess whether the epithelially induced pADSC displayed other typical features of a tight epithelium, we monitored changes in trans-epithelial electrical resistance (TEER) over time in confluent epithelialized pADSC as compared to confluent, non-induced controls. There was an increase in the TEER in pADSCs grown in epithelial induction media, consistent with increased tight junction formation, that plateaued after 2 weeks (Fig. 1E). As pADSCs do not express endothelial markers as shown in previous studies (Guasti et al., 2012, New et al., 2015) and in Suppl. Fig. 2, these data are consistent with their ability to undergo epithelial differentiation.

\subsection{D cultures of PADSC-derived Cartilage and Epithelial Cells}

In order to assess the potential to generate an epithelium-lined cartilage construct from pADSCs from the same patient, we employed micromasses as our model system. Chondrogenically-induced micromasses expressed collagen II, but little to no CK-18 (Fig. 2A). The chondrogenic marker, collagen 2 and the epithelial marker, CK18, were both expressed in those chondrogenically-induced micromasses with the additional epithelial-differentiated ADSC coating (termed "epith-chondro"). Importantly, no cell within these micromasses was noted to express both markers: cells 
were either positive for collagen II or CK-18 (Fig. 2B, negative controls can be seen in Fig. 2C). Control micromasses expressed both collagen II and CK-18, but to a lesser extent than in the experimental conditions and in a less organised fashion (data not shown). Chondrogenically-induced micromasses possessed tight bundles of F-actin (Fig. 2D), whereas F-actin in association with cell-cell adhesions were seen in those micromasses with an epithelial element (epith-chondro micromasses) (Fig. 2E-F).

\subsection{Adipose derived-stem cell (ADSC) behaviour on POSS-PCL}

In order to engineer a safe and effective upper airways replacement for children, a scaffold that allows scaling up for the production of large grafts would be highly beneficial. We first compared the behaviour of ADSCs seeded onto 2D POSS-PCL, a bioabsorbable nanoscaffold and plastic in terms of attachment, survival, proliferation and differentiation. Both human paediatric and chick-derived ADSCs adhered onto 2D POSS-PCL discs (Fig. 3A). Cell viability and proliferative capacity of ADSC seeded onto on POSS-PCL nanoscaffold was analysed. Cell death of pADSCs was observed to be low both when the cells were seeded on POSS-PCL and plastic (Fig.3B). DNA synthesis analysis by BrdU incorporation demonstrated that pADSCs proliferate on POSS-PCL (Fig 3C).

We then investigated the potential of pADSCs seeded on 2D POSS-PCL discs to differentiate towards the mesenchymal tissues: adipose tissue, bone and cartilage. When seeded on 2D POSS-PCL discs, pADSCs were still capable of differentiating along the adipogenic lineage - as noted by the appearance of oil droplet-laden cells (Fig. 4A), osteogenic lineage - as noted by the appearance of mineralized nodules (Fig. 4B), which stained positive for Alizarin Red (not shown), and chondrogenic - as noted by a change in morphology and an increase in extracellular matrix when compared to the 
control (Fig. 4C and 4D respectively). The ability of pADSC to differentiate towards the epithelial-like phenotype when seeded on 2D POSS-PCL discs (Fig. 5A-B) was also assessed. A change in morphology as well as up-regulation in CK-18 gene expression was observed when the cells were differentiated on POSS-PCL comparable to that observed on plastic (Fig. 5C).

Finally, we investigated whether the ADSCs were able to migrate throughout the $1 \mathrm{~mm}$ porous 3D POSS-PCL scaffold, undergo chondrogenic differentiation and secrete chondroid matrix. 3D POSS-PCL contains irregular shaped pores in a range of sizes, from small pores to large cavities (Fig. 6A). Pediatric ADSC and EGFP-expressing chick ADSC were observed to adhere and migrate through the 3D POSS-PCL nanoscaffold without the need for additional adhesion molecules, populating the whole depth indicating efficient migration throughout the scaffold (Fig. 6B). Chick ADSCseeded in POSS-PCL nanoscaffold were able to differentiate towards the chondrogenic lineage and deposit Alcian Blue-positive chondroid matrix (Fig. 6C). This was not observed in controls (Fig. 6c'). In addition, staining for the chondrogenic marker, aggrecan, was detected in scaffolds containing differentiated chick ADSCs, but not in scaffolds seeded with undifferentiated cells or unseeded (Fig. 6D-F). POSS-PCL also supported chondrogenic differentiation of human cells as indicated by collagen-II expression in pADSC (Fig. 6G). Finally, pADSCs were induced to differentiate along the epithelial lineage on the POSS-PCL scaffolds for 3 weeks. Tight junction formation could be observed by ZO-1 staining both on POSS-PCL alone and POSS-PCL previously cellularised with chondrogenically induced-pADSCs (Fig. 6H-J), although high quality imaging of these cells was difficult because of the lack of transparency, background fluorescence and uneven surface of the scaffold (Fig. 6G-H). Attempts to 
section the epithelialized scaffold to achieve better quality imaging was not successful because the differentiated epithelium detached during sectioning.

\subsection{Biocompatibility of ADSC-seeded POSS-PCL}

CAM-grafting was used to monitor the response of the host vasculature and cells to the 3D POSS-PCL nanoscaffold in vivo. After 8 days implantation on the CAM, blood vessels were observed to penetrate the unseeded POSS-PCL nanoscaffold (Fig. 7A). The attachment of the CAM to the unseeded POSS-PCL nanoscaffold could be seen ex ovo (Fig. 7B) and nuclear staining identified the presence of host cells throughout the scaffold (Fig. 7C). In ovo CAM-grafting of ADSC-POSS-PCL nanoscaffold composites suggested vascularization by host tissue without apparent negative consequences: both control and chondrogenically-induced ADSC-POSS-PCL nanoscaffolds were encased by vessels (Fig. 7D-F). ADSC-POSS-PCL nanoscaffolds induced chondrogenically were also readily encapsulated by host tissue (Fig. 7E-F) and maintained the differentiated phenotype (Fig. 6D). No aggrecan reactivity was observed in the noncellularized CAM-grafted scaffolds indicating that although some host cell migrated into the scaffold, they did not contribute to cartilage formation (Fig. 6F). Immunohistochemical analysis of the infiltrated host cells showed expression of a marker specific for chick monocytes and macrophages (Fig. 7G). Such expression was not observed in the non-grafted ADSC-seeded POSS-PCL nanoscaffolds (Suppl. Fig. 4). ADSC-POSS-PCL nanoscaffolds induced chondrogenically and then lined with epithelial-differentiated ADSCs, termed epith-chondro ADSC-POSS-PCL, were also readily encased by vessels, and this was found to be the case (Fig. $7 \mathrm{H})$. 


\section{Discussion}

This study shows the robust nature of pADSCs to maintain their viability and differentiated phenotype when challenged with different environments, supporting the therapeutic potential of these somatic stem cells. Generation of novel 3D structures containing two different cell types, epithelial and chondrogenic cells, from pADSCs demonstrates, for the first time to our knowledge, that in addition to the mesenchymaldifferentiation potential, pADSCs have the potential to transdifferentiate towards an epithelial phenotype, that is usually associated with another germ line. Taking together the negligible expression of hematopoietic progenitor and endothelial cell markers in pADSCs (e.g. $\%$ of $\mathrm{CD} 31=0.49 \pm 0.30$; see New et al., 2015), the rare keratin expressing cells observed only in control cells grown on laminin, and in regions of high cell density, and the fact that treatment with retinoic acid blocks cell proliferation, it is most unlikely that induction of epithelial markers observed in most cells in the cultures is due to subset of non-mesenchymal cells present in the pADSC cultures. Furthermore, we have observed that clonal cell populations maintain the same ability to differentiate along mesenchymal and neuroectodermal lineages (New et al, in preparation).

Engineering an upper airway cellularised construct suitable for paediatric reconstruction requires the addition of a scaffold capable of supporting cells differentiation and matrix production in a dynamic in vivo environment. Here we have tested a biodegradable nanoscaffold incorporating POSS nanoparticles and polycaprolactone (POSS-PCL) for its ability to support both chondrogenic and epithelial differentiation. We demonstrate the differentiation potential of human somatic stem cells, specifically pADSCs, on POSS-PCL potentially unlocking their application in future studies in mammals prior to clinical trials. 


\subsection{Towards the Generation of an Epithelium and Cartilage Construct}

The ability to engineer a structure that contains both stable cartilage and epithelium is important for engineering of the airways, in which a functional epithelium is widely considered essential for achieving a favourable clinical outcome following airway replacement or repair. Some spontaneous re-epithelialization of airway cartilage has been reported in small animal models particularly when cellularised scaffolds are used, but in patients the process appears slow and generates variable quality epithelium (Hamilton et al., 2014). Generation of a 3D epithelium-lined cartilage construct is challenging, but achieving this from a single autologous source would simplify the tissue engineering process, potentially cutting costs and the need for multiple surgical procedures. We propose that pADSCs hold great promise for this purpose.

In our study, all the human pADSC lines tested were able to reproducibly differentiate towards an epithelial-like cell upon induction in a retinoic acidsupplemented medium, as shown by morphology and the modulation of specific epithelial markers at the mRNA and protein level. Retinoic acid plays an essential role in cell differentiation, development and regeneration; furthermore the pluripotent stem cell field have established this small molecule as a known agent that affects transcription factors and regulates gene expression (Wu et al., 2014, Zhang et al., 2015, Metallo et al., 2008). The group of Baer demonstrated that retinoic acid-induced human adult ADSCs can transdifferentiate towards an epithelial-like cell, demonstrating a change in morphology and increase in CK-18 protein expression, a type I cytokeratin typical of simple columnar epithelial cells, (Brzoska et al., 2005). This report is consistent with our findings that CK-18 is up-regulated in pADSCs, both at the mRNA and protein level, upon induction of epithelial differentiation. Tight junction formation is a key indicator of epithelial differentiation and can be visualized by the classically 
accepted tight junction marker ZO-1. Our study shows that $\mathrm{ZO}-1$ is expressed in pADSCs and upon epithelial differentiation induction is translocated from the cytoplasm to the plasma membrane as it could clearly be seen encircling the epithelially-differentiated pADSCs. Hence, pADSCs like adult ADSCs (Brzoska et al., 2005, Griesche et al., 2012), can display epithelial characteristics.

Here, we provide additional evidence of the epithelial-like nature of these ADSC-derived cells. The epithelial-like cells we have produced from the pADSC can form a barrier, a vital feature of the epithelium lining, as indicated by the increase in TEER upon their epithelial induction; this further confirms the formation of tightjunctions between cells indicated by ZO-1. While the decrease in TEER observed at 3 weeks may be due to the epithelium becoming over-confluent and peeling off in places, it also suggests that an optimisation of the protocol is required for maintenance and full maturation of the epithelium. Notwithstanding these limitations, our results suggest pADSC transdifferentiation towards a cell that not only resembles an epithelial cell in terms of phenotype, but also in terms of function. An air liquid interface system, classically used to differentiate primary bronchial epithelial cells into a functional ciliated barrier-forming epithelium (Lin et al., 2007), may need to be employed to fully mature epithelium generated from pADSCs and this will be subject of further research.

The use of the micromass in vitro system has allowed us to explore the ability of the pADSCs to generate an epithelium-lined cartilage construct. CK-18-positive cells were apparent on the cartilaginous matrix, further investigation of the epith-chondro micromasses revealed a remodelling of the F-actin in some cells consistent with a mesenchymal-epithelial transition (Haynes et al., 2011). This is first proof-of-principle study to demonstrate that a $3 \mathrm{D}$ structure can be created from one type of somatic stem 
cell that harbours two phenotypically-different cell types from two different germ layers. Importantly, the potential for pADSCs to successfully generate both of the two different cell types appears to be a general feature of these cells, as it was observed in lines generated from several different patients in this study as well as in the course of our ongoing related work.

\section{2. pADSCs can differentiate in POSS-PCL and form biocompatible constructs}

Previously, tissue engineered constructs based on decellularised "biologic" scaffolds and seeded with MSC and respiratory epithelial cells have been used clinically with some success (Elliott et al., 2012, Gonfiotti et al., 2014, Hamilton et al., 2015, Macchiarini et al., 2008). Although such biologic matrices have important theoretical advantages, the decellularisation process is often very harsh and biomechanical and biochemical deterioration is often noted (Haykal et al., 2012, Sun et al., 2015). Others continue work to establish the optimal decellularisation protocols (Jungebluth et al., 2009, Zang et al., 2012, Kiselevsky et al., 2011, Bijonowski et al., 2013, Baiguera et al., 2014, Weymann et al., 2015). However, tissue engineering approaches reliant on cadaveric tissue are limited by the shortage of donors, potential infection and suitability of available tissue.

Here, we used a biodegradable synthetic polymer, POSS-PCL which has already shown promise for applications including trachea replacement wherein it was shown to support the proliferation of bone marrow mesenchymal stem cells and bronchial epithelial cells for up to 14 days (Teoh et al., 2015). However, to our knowledge no other study has shown that this scaffold material supports the differentiation of stem cells. An optimal interaction between scaffold and cells is vital: the scaffold is required to not only act as a framework for the cells, but also promote 
their growth and differentiation. Our results show that POSS-PCL nanoscaffolds not only support the survival of pADSCs, but also maintain their differentiation potential. Both human paediatric and chick ADSCs colonised the POSS-PCL nanoscaffolds and deposited Alcian blue-positive chondroid matrix. Importantly, the POSS-PCL nanoscaffold was able to retain the chondroid matrix deposited by the ADSCs. Chondrogenically-induced samples expressed high levels of aggrecan on a protein level, similar to that shown for pADSCs seeded in the non-biodegradable POSS-PCU nanoscaffold in our previous study (Guasti et al., 2014). POSS-PCL nanoscaffold was also conducive for the differentiation of pADSCs towards an epithelial-like cell, although it is envisaged that derivitisation of scaffold or coating with a basement membrane protein will be required to support differentiation towards a more mature epithelial phenotype.

Biocompatibility of tissue engineered constructs is critical and vascularisation is considered a major determinant of the success of any implanted engineered construct (Auger et al., 2013). Cartilage is an avascular tissue, with nutrients supplied by diffusion. Nonetheless, encasing of a tissue-engineered cartilage construct by host vessels is important for its anchorage in situ, to prevent extrusion and maintain its homeostasis. This study demonstrates the biocompatibility of acellular and cellularised POSS-PCL nanoscaffolds seeded with either control or chondrogenically-induced pADSCs. Not only were the chondrogenically-induced ADSC-seeded POSS-PCL samples enwrapped by host vessels, suggesting that risk of extrusion would be low, but also an infiltration of immunologically active host cells was noted. The presence of immune cells has been shown to be required for optimal regeneration, degradation of 
scaffold and overall implant success (Jones, 2008, Bartaula-Brevik et al., 2014, Brown et al., 2012).

The ability of the POSS-PCL nanoscaffolds to support differentiation of pADSCs towards both desired cell phenotypes, and the biocompatibility of pADSCnanoscaffolds in short term in ovo studies provides a strong basis for progressing to studies in larger animals. Long term in vivo studies for the repair of critical size defects are required to measure immune response, ensure integration of the ADSC-seeded POSS-PCL nanoscaffold, and assess the ability of the engineered composite to maintain structure and differentiated phenotype.

This study has important implications for bioengineering of the airways and confirms the plastic-nature of paediatric ADSC, specifically their ability to generate a tight barrier-forming epithelium. Further work to establish the mechanical strength of the composites and rate of degradation is necessary to verify the suitability of their clinical long-term use. Clinical application of this technology in upper airways reconstruction appears feasible.

\section{Acknowledgements}

This work was supported by Newlife Foundation, an UCL Impact Studentship with sponsorship from Mrs Hana Thalova, The RCS (Royal College of Surgeons of England) Bond Research Training Fellowship and GOSH NIHR Biomedical Research Centre. We are grateful to Arnold Darbyshire for the POSS-PCL synthesis and his help with preparing the nanoscaffolds, Calypso Varotsis for technical support, and lastly, Dr Bertrand Vernay and Dr Dale Moulding at the ICH Microscopy Facility.

Disclosure of Potential Conflicts of Interest: Professor Birchall has acted as consultant to Videregen Ltd and Reneuron Ltd. 


\section{References}

AUGER, F. A., GIBOT, L. \& LACROIX, D. 2013. The pivotal role of vascularization in tissue engineering. Annu Rev Biomed Eng, 15, 177-200.

BAER, P. C., BRZOSKA, M. \& GEIGER, H. 2011. Epithelial differentiation of human adiposederived stem cells. Methods Mol Biol, 702, 289-98.

BAIGUERA, S., DEL GAUDIO, C., KUEVDA, E., GONFIOTTI, A., BIANCO, A. \& MACCHIARINI, P. 2014. Dynamic decellularization and cross-linking of rat tracheal matrix. Biomaterials, 35, 6344-50.

BARTAULA-BREVIK, S., PEDERSEN, T. O., BLOIS, A. L., PAPADAKOU, P., FINNEWISTRAND, A., XUE, Y., BOLSTAD, A. I. \& MUSTAFA, K. 2014. Leukocyte transmigration into tissue-engineered constructs is influenced by endothelial cells through Toll-like receptor signaling. Stem Cell Res Ther, 5, 143.

BIJONOWSKI, B. M., MILLER, W. M. \& WERTHEIM, J. A. 2013. Bioreactor design for perfusion-based, highly-vascularized organ regeneration. Curr Opin Chem Eng, 2, 3240.

BROWN, B. N., RATNER, B. D., GOODMAN, S. B., AMAR, S. \& BADYLAK, S. F. 2012. Macrophage polarization: an opportunity for improved outcomes in biomaterials and regenerative medicine. Biomaterials, 33, 3792-802.

BRZOSKA, M., GEIGER, H., GAUER, S. \& BAER, P. 2005. Epithelial differentiation of human adipose tissue-derived adult stem cells. Biochem Biophys Res Commun, 330, $142-50$.

COLAZZO, F., CHESTER, A. H., TAYLOR, P. M. \& YACOUB, M. H. 2010. Induction of mesenchymal to endothelial transformation of adipose-derived stem cells. $J$ Heart Valve Dis, 19, 736-44.

CSOBONYEIOVA, M., POLAK, S., KOLLER, J. \& DANISOVIC, L. 2015. Induced pluripotent stem cells and their implication for regenerative medicine. Cell Tissue Bank, $16,171-80$.

CUKIERMAN, E., PANKOV, R., STEVENS, D. R. \& YAMADA, K. M. 2001. Taking cellmatrix adhesions to the third dimension. Science, 294, 1708-12.

ELLIOTT, M. J., DE COPPI, P., SPEGGIORIN, S., ROEBUCK, D., BUTLER, C. R., SAMUEL, E., CROWLEY, C., MCLAREN, C., FIERENS, A., VONDRYS, D., COCHRANE, L., JEPHSON, C., JANES, S., BEAUMONT, N. J., COGAN, T., BADER, A., SEIFALIAN, A. M., HSUAN, J. J., LOWDELL, M. W. \& BIRCHALL, M. A. 2012. Stem-cell-based, tissue engineered tracheal replacement in a child: a 2-year follow-up study. Lancet, 380, 994-1000.

FATTAH, A., SEBIRE, N. J. \& BULSTRODE, N. W. 2010. Donor site reconstitution for ear reconstruction. J Plast Reconstr Aesthet Surg, 63, 1459-65.

FIRMIN, F. 2010. State-of-the-art autogenous ear reconstruction in cases of microtia. Adv Otorhinolaryngol, 68, 25-52. 
FISCHER, H., EPPSTEIN, R. J., VON GREGORY, H. F. \& GUBISCH, W. 2014. Nasal reconstruction in heminasal deficiency (proboscis lateralis): two case reports, with airway reconstruction in one case. Facial Plast Surg, 30, 365-70.

GANESAN, S., COMSTOCK, A. T. \& SAJJAN, U. S. 2013. Barrier function of airway tract epithelium. Tissue Barriers, 1, e24997.

GIMBLE, J. M., GUILAK, F. \& BUNNELL, B. A. 2010. Clinical and preclinical translation of cell-based therapies using adipose tissue-derived cells. Stem Cell Res Ther, 1, 19.

GONFIOTTI, A., JAUS, M. O., BARALE, D., BAIGUERA, S., COMIN, C., LAVORINI, F., FONTANA, G., SIBILA, O., ROMBOLA, G., JUNGEBLUTH, P. \& MACCHIARINI, P. 2014. The first tissue-engineered airway transplantation: 5-year follow-up results. Lancet, 383, 238-44.

GRIESCHE, N., BEREITER-HAHN, J., GEIGER, H., SCHUBERT, R. \& BAER, P. C. 2012. During epithelial differentiation of human adipose-derived stromal/stem cells, expression of zonula occludens protein-1 is induced by a combination of retinoic acid, activin-A and bone morphogenetic protein-7. Cytotherapy, 14, 61-9.

GUASTI, L., PRASONGCHEAN, W., KLEFTOURIS, G., MUKHERJEE, S., THRASHER, A. J., BULSTRODE, N. W. \& FERRETTI, P. 2012. High plasticity of pediatric adipose tissue-derived stem cells: too much for selective skeletogenic differentiation? Stem Cells Transl Med, 1, 384-95.

GUASTI, L., VAGASKA, B., BULSTRODE, N. W., SEIFALIAN, A. M. \& FERRETTI, P. 2014. Chondrogenic differentiation of adipose tissue-derived stem cells within nanocaged POSS-PCU scaffolds: a new tool for nanomedicine. Nanomedicine, 10, 27989.

GUPTA, A., VARA, D. S., PUNSHON, G., SALES, K. M., WINSLET, M. C. \& SEIFALIAN, A. M. 2009. In vitro small intestinal epithelial cell growth on a nanocomposite polycaprolactone scaffold. Biotechnol Appl Biochem, 54, 221-9.

HAMILTON, N., BULLOCK, A. J., MACNEIL, S., JANES, S. M. \& BIRCHALL, M. 2014. Tissue engineering airway mucosa: a systematic review. Laryngoscope, 124, 961-8.

HAMILTON, N. J., KANANI, M., ROEBUCK, D. J., HEWITT, R. J., CETTO, R., CULMESEYMOUR, E. J., TOLL, E., BATES, A. J., COMERFORD, A. P., MCLAREN, C. A., BUTLER, C. R., CROWLEY, C., MCINTYRE, D., SEBIRE, N. J., JANES, S. M., O'CALLAGHAN, C., MASON, C., DE COPPI, P., LOWDELL, M. W., ELLIOTT, M. J. \& BIRCHALL, M. A. 2015. Tissue-Engineered Tracheal Replacement in a Child: A 4-Year Follow-Up Study. Am J Transplant, 15, $2750-7$.

HAYKAL, S., SOLEAS, J. P., SALNA, M., HOFER, S. O. \& WADDELL, T. K. 2012. Evaluation of the structural integrity and extracellular matrix components of tracheal allografts following cyclical decellularization techniques: comparison of three protocols. Tissue Eng Part C Methods, 18, 614-23.

HAYNES, J., SRIVASTAVA, J., MADSON, N., WITTMANN, T. \& BARBER, D. L. 2011. Dynamic actin remodeling during epithelial-mesenchymal transition depends on increased moesin expression. Mol Biol Cell, 22, 4750-64. 
HENEIDI, S., SIMERMAN, A. A., KELLER, E., SINGH, P., LI, X., DUMESIC, D. A. \& CHAZENBALK, G. 2013. Awakened by cellular stress: isolation and characterization of a novel population of pluripotent stem cells derived from human adipose tissue. PLoS One, 8, e64752.

JONES, K. S. 2008. Effects of biomaterial-induced inflammation on fibrosis and rejection. Semin Immunol, 20, 130-6.

JUNGEBLUTH, P., ALICI, E., BAIGUERA, S., LE BLANC, K., BLOMBERG, P., BOZOKY, B., CROWLEY, C., EINARSSON, O., GRINNEMO, K. H., GUDBJARTSSON, T., LE GUYADER, S., HENRIKSSON, G., HERMANSON, O., JUTO, J. E., LEIDNER, B., LILJA, T., LISKA, J., LUEDDE, T., LUNDIN, V., MOLL, G., NILSSON, B., RODERBURG, C., STROMBLAD, S., SUTLU, T., TEIXEIRA, A. I., WATZ, E., SEIFALIAN, A. \& MACCHIARINI, P. 2011. Tracheobronchial transplantation with a stem-cell-seeded bioartificial nanocomposite: a proof-of-concept study. Lancet, 378, 1997-2004.

JUNGEBLUTH, P., GO, T., ASNAGHI, A., BELliNi, S., MARTORELL, J., CALORE, C., URBANI, L., OSTERTAG, H., MANTERO, S., CONCONI, M. T. \& MACCHIARINI, P. 2009. Structural and morphologic evaluation of a novel detergent-enzymatic tissueengineered tracheal tubular matrix. J Thorac Cardiovasc Surg, 138, 586-93; discussion 592-3.

KIMBREL, E. A. \& LANZA, R. 2015. Current status of pluripotent stem cells: moving the first therapies to the clinic. Nat Rev Drug Discov, 14, 681-92.

KISELEVSKY, M. V., ANISIMOVA, N. Y., LEBEDINSKAYA, O. V., POLOTSKII, B. E. \& DAVYDOV, M. I. 2011. Optimization of a method for preparation and repopulation of the tracheal matrix for allogenic transplantation. Bull Exp Biol Med, 151, 107-13.

LIN, H., LI, H., CHO, H. J., BIAN, S., ROH, H. J., LEE, M. K., KIM, J. S., CHUNG, S. J., SHIM, C. K. \& KIM, D. D. 2007. Air-liquid interface (ALI) culture of human bronchial epithelial cell monolayers as an in vitro model for airway drug transport studies. $J$ Pharm Sci, 96, 341-50.

MACCHIARINI, P., JUNGEBLUTH, P., GO, T., ASNAGHI, M. A., REES, L. E., COGAN, T. A., DODSON, A., MARTORELL, J., BELLINI, S., PARNIGOTTO, P. P., DICKINSON, S. C., HOLLANDER, A. P., MANTERO, S., CONCONI, M. T. \& BIRCHALL, M. A. 2008. Clinical transplantation of a tissue-engineered airway. Lancet, 372, 2023-30.

MCGREW, M. J., SHERMAN, A., ELLARD, F. M., LILLICO, S. G., GILHOOLEY, H. J., KINGSMAN, A. J., MITROPHANOUS, K. A. \& SANG, H. 2004. Efficient production of germline transgenic chickens using lentiviral vectors. EMBO Rep, 5, 728-33.

METALLO, C. M., JI, L., DE PABLO, J. J. \& PALECEK, S. P. 2008. Retinoic acid and bone morphogenetic protein signaling synergize to efficiently direct epithelial differentiation of human embryonic stem cells. Stem Cells, 26, 372-80.

MORISSETTE MARTIN, P., MAUX, A., LATERREUR, V., MAYRAND, D., V, L. G., MOULIN, V. J. \& FRADETTE, J. 2015. Enhancing repair of full-thickness excisional wounds in a murine model: Impact of tissue-engineered biological dressings featuring human differentiated adipocytes. Acta Biomater, 22, 39-49. 
NEW, S. E., ALVAREZ-GONZALEZ, C., VAGASKA, B., GOMEZ, S. G., BULSTRODE, N. W., MADRIGAL, A. \& FERRETTI, P. 2015. A matter of identity - Phenotype and differentiation potential of human somatic stem cells. Stem Cell Res, 15, 1-13.

SHINGYOCHI, Y., ORBAY, H. \& MIZUNO, H. 2015. Adipose-derived stem cells for wound repair and regeneration. Expert Opin Biol Ther, 15, 1285-92.

STRONG, A. L., CEDERNA, P. S., RUBIN, J. P., COLEMAN, S. R. \& LEVI, B. 2015. The Current State of Fat Grafting: A Review of Harvesting, Processing, and Injection Techniques. Plast Reconstr Surg, 136, 897-912.

SUN, F., PAN, S., SHI, H. C., ZHANG, F. B., ZHANG, W. D., YE, G., LIU, X. C., ZHANG, S. Q., ZHONG, C. H. \& YUAN, X. L. 2015. Structural integrity, immunogenicity and biomechanical evaluation of rabbit decelluarized tracheal matrix. J Biomed Mater Res A, 103, 1509-19.

TEOH, G. Z., CROWLEY, C., BIRCHALL, M. A. \& SEIFALIAN, A. M. 2015. Development of resorbable nanocomposite tracheal and bronchial scaffolds for paediatric applications. Br J Surg, 102, e140-50.

WEYMANN, A., PATIL, N. P., SABASHNIKOV, A., KORKMAZ, S., LI, S., SOOS, P., ISHTOK, R., CHAIMOW, N., PATZOLD, I., CZERNY, N., SCHMACK, B., POPOV, A. F., SIMON, A. R., KARCK, M. \& SZABO, G. 2015. Perfusion-Decellularization of Porcine Lung and Trachea for Respiratory Bioengineering. Artif Organs.

WU, C. Y., FENG, X. \& WEI, L. N. 2014. Coordinated repressive chromatin-remodeling of Oct4 and Nanog genes in RA-induced differentiation of embryonic stem cells involves RIP140. Nucleic Acids Res, 42, 4306-17.

ZANG, M., ZHANG, Q., CHANG, E. I., MATHUR, A. B. \& YU, P. 2012. Decellularized tracheal matrix scaffold for tissue engineering. Plast Reconstr Surg, 130, 532-40.

ZHANG, J., GAO, Y., YU, M., WU, H., AI, Z., WU, Y., LIU, H., DU, J., GUO, Z. \& ZHANG, Y. 2015. Retinoic Acid Induces Embryonic Stem Cell Differentiation by Altering Both Encoding RNA and microRNA Expression. PLoS One, 10, e0132566.

ZHANG, Z. N. \& XU, Y. 2012. Progress and bottleneck in induced pluripotency. Cell Regen (Lond), 1,5 . 


\section{Figure Legends}

Figure 1. Paediatric ADSCs (pADSCs) transdifferentiate towards an epithelial-like phenotype. (A-C) Immunostaining of pADSCs maintained on Matrigel ${ }^{\mathrm{TM}_{-}}$-coated plastic for 3 weeks for the epithelial markers, zonula occludens-1 (ZO-1, red) and cytokeratin18 (CK-18, green). (A) control medium; low cytoplasmic expression of ZO-1 and occasional CK-18 is observed. (B-C) epithelial induction medium; most cells express CK-18 and ZO-1 is localized at the tight junctions. (D) CK-18 and ZO-1 mRNA expression detected by RT-qPCR; there is a significant increase in CK-18 transcript (*: $\mathrm{p}<0.05$ ) whilst ZO-1 mRNA expression remains unchanged. (E) Trans-epithelial electrical resistance (TEER); TEER, a measurement of tight-junction function, increases in epithelially-induced pADSCs. Experiments were performed on ADSCs isolated from at least four paediatric patients, with the exception of the TEER experiments that were performed in triplicate on two pADSC lines. Mean \pm SEM.

\section{Figure 2. Generation of an epithelium-lined cartilage from pADSCs. Timeline} outlines the experimental strategy for co-culture experiments. (A) Chondrogenicallydifferentiated pADSC-micromasses (chon) express collagen-II (col-II, red). (B) pADSC epithelial and chondrogenically-differentiated micromasses (epi-chon) express CK-18positive epithelial differentiated ADSCs and collagen-II-positive chondrogenic ADSCs (col-II, red; CK-18, green). (C) Negative control with secondary antibody alone. (D) Chondrogenically-differentiated pADSC-micromasses display F-actin (green) organized into thick parallel bundles. (E-F) pADSC epithelial and chondrogenically-differentiated micromasses (epi-chon) exhibit lower levels of F-actin expression, some of which associated with cell-cell adhesions. 
Figure 3. Viability and proliferation of ADSCs on monolayer POSS-PCL nanoscaffold. (A) GFP- expressing chick ADSCs seeded on 2D POSS-PCL. (B) Percentage of dead cells detected by PI staining in pADSCs seeded onto either plastic or nanoscaffold. (C) Percentage of BrdU positive nuclei in pADSCs seeded onto either plastic or nanoscaffold. (B \& C) The experiments were performed on ADSCs isolated from three paediatric patients, Mean \pm SEM.

Figure 4. Differentiation potential of ADSCs on monolayer 2D POSS-PCL nanoscaffold. Representative brightfield images depicting morphology of pADSCs differentiated towards either adipogenic (A), osteogenic (B), or chondrogenic lineages (C), compared to pADSCs maintained under control conditions (D). (A-D) Scale bars equal to $100 \mu \mathrm{m}$.

Figure 5. Epithelial differentiation of pADSCs on monolayer 2D POSS-PCL nanoscaffold. Representative brightfield images depicting the similar morphology of pADSCs differentiated towards the epithelial lineage seeded onto plastic (A) and POSSPCL nanoscaffold (B). (C) CK-18 mRNA expression is upregulated in pADSCs seeded on both plastic and POSS-PCL.

Figure 6. Migration and chondrogenic differentiation of GFP-expressing chick ADSC and pADSCs and epithelial differentiation of pADSCs in 3D POSS-PCL nanoscaffolds. Sections of unseeded and cellularized nanoscaffolds after 3 weeks in culture are shown in (A-F) whereas (G-J) show cells on the top surface of the nanoscaffold following epithelial differentiation induction. (A) Microstructure of unseeded nanoscaffold (blue), (B) GFP-expressing chick ADSC (green) seeded within the nanoscaffold (blue). (C) Alcian blue-stained chick ADSC-nanoscaffold composites 
incubated in chondrogenic media; positive chondroid matrix is apparent (arrow); (c') this is in contrast to composites incubated under control conditions. (D) The chondrogenic marker, aggrecan, is expressed in the GFP-expressing chick ADSCnanoscaffold composites incubated in chondrogenic medium. (D-F) Aggrecan staining of CAM-grafted scaffolds seeded with: chondrogenically differentiated cADSC (E), undifferentiated cADSCs (E) and unseeded scaffolds (F). Note that aggrecan deposition (red) is observed only upon chondrogenic differentiation. Images are at the same magnification. (G) Collagen-II staining following chondrogenic differentiation of pADSC seeded on POSS-PCL; g': no primary antibody control. (H-J) Surface images of ZO-1(tight junction marker) staining of pADSCs following epithelial differentiation on 3D porous POSS-PCL. Low (H) and high (I) magnification of epithelially differentiated pADSC; in (H) reflection is used to visualise the scaffold surface (grey). (I) Surface image of epithelially differentiated pADSC co-cultured with chondrogenic differentiated pADSC on POSS-PCL. (K) Control staining (secondary antibody only) of epithelially differentiated pADSC. Scale bars in $\mathrm{H}-\mathrm{K}=20 \mu \mathrm{m}$.

Figure 7. Biocompatibility of POSS-PCL nanoscaffolds in vivo. (A-C) Characterization of unseeded POSS-PCL by chorioallantoic membrane (CAM) grafting: (A) Vascularization of unseeded POSS-PCL nanoscaffolds (arrows point to host vessels). (B) Attachment of unseeded nanoscaffold to the CAM (scale bar $500 \mu \mathrm{m}$ ). (C) Hoechst 33258 nucleiar staining of unseeded nanoscaffold; note host cell infiltration. (D-H) In vivo characterization of chick ADSC-seeded nanoscaffold: (D-E) Vascularization of control, (D) and chondrogenically-induced (E) chick ADSCnanoscaffold. (F) Vascularization of chondrogenically-induced pADSC-nanoscaffold. (G) Stain of CAM-grafted pADSC-nanoscaffold with an antibody specific for chicken 
monocytes and macrophages; positive host cells (brown) are observed; nuclei are counterstained with haematoxylin (blue). (H) Vascularisation of epithelium-lined chondrogenically-induced pADSC-nanoscaffold. (A-H) Scale bars equal to $500 \mu \mathrm{m}$, unless otherwise stated. 

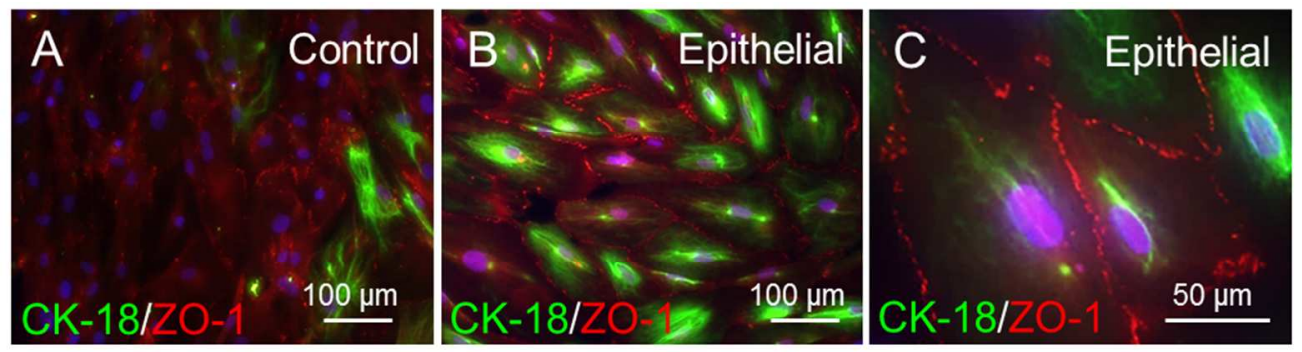

D

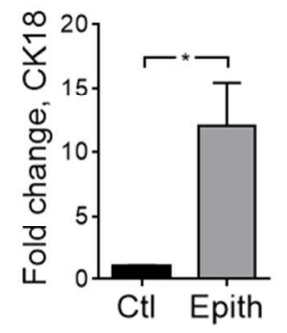

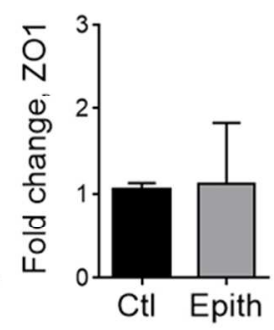

E

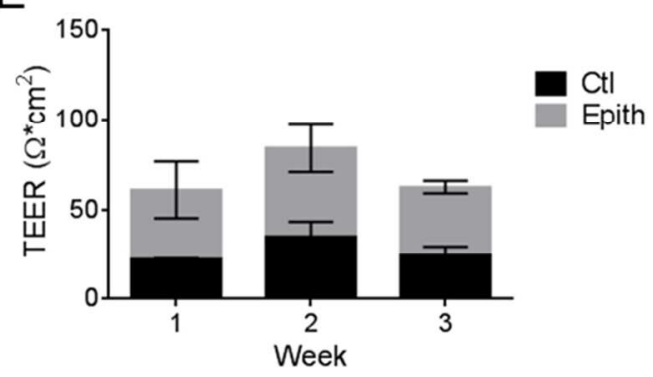

Figure 1. Paediatric ADSCs (pADSCs) transdifferentiate towards an epithelial-like phenotype. (A) pADSCs seeded on Matrigel ${ }^{\mathrm{TM}}$-coated plastic and cultured under control conditions express cytoplasmic zonula occludens-1 (ZO-1, red) and little-to-nil epithelial marker cytokeratin-18 (CK-18, green), (B \& C) pADSCs cultured with retinoic acid express ZO-1 along the tight junctions and CK-18 in abundance. (D) CK-18 mRNA expression increases when the pADSCs are cultured towards an epithelial phenotype using a retinoic acidsupplemented media, whilst ZO-1 mRNA expression remains unchanged. (E) Trans-epithelial electrical resistance (TEER) - a measurement of tight-junction function - increases in pADSCs induced towards an epithelial phenotype. Experiments were performed on ADSCs isolated from at least four paediatric patients, with the exception of the TEER experiments that were performed in triplicate on two pADSC lines. Mean \pm SEM. 

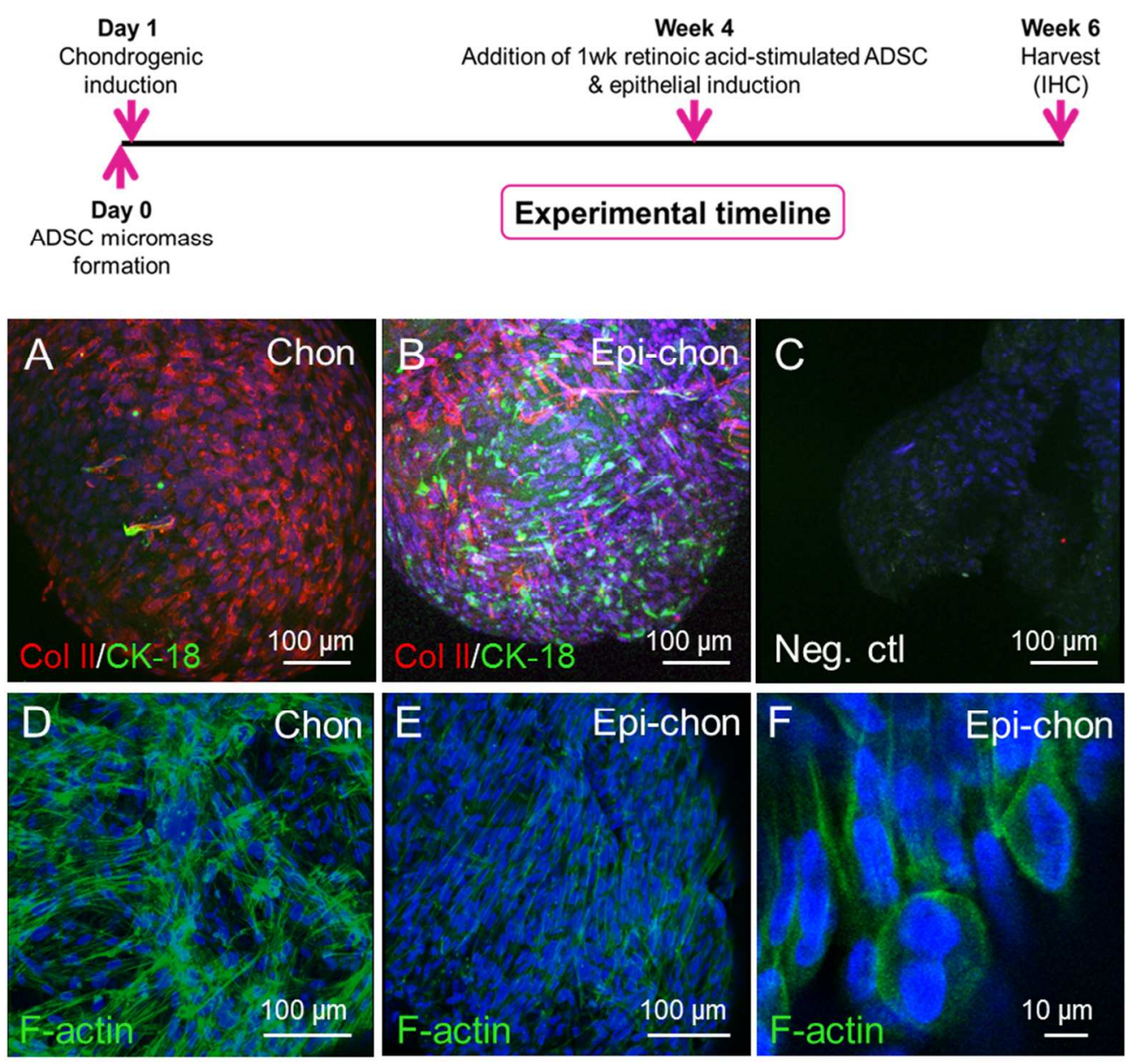

Figure 2. Generation of an epithelium-lined cartilage. Timeline outlining the experimental strategy for coculture experiments. (A) Chondrogenically-differentiated pADSC-micromasses (chon) express collagen-II (col-II, red). (B) pADSC epithelial and chondrogenically-differentiated micromasses (epi-chon) express CK18-positive epithelial differentiated ADSCs and collagen-II-positive chondrogenic ADSCs (col-II, red; CK-18, green). (C) Negative control with secondary antibody alone. (D) Chondrogenically-differentiated pADSC-

micromasses display F-actin (green) organized into thick parallel bundles. (E-F) pADSC epithelial and chondrogenically-differentiated micromasses (epi-chon) exhibit lower levels of F-actin expression, some of which associated with cell-cell adhesions. $162 \times 153 \mathrm{~mm}(150 \times 150 \mathrm{DPI})$ 

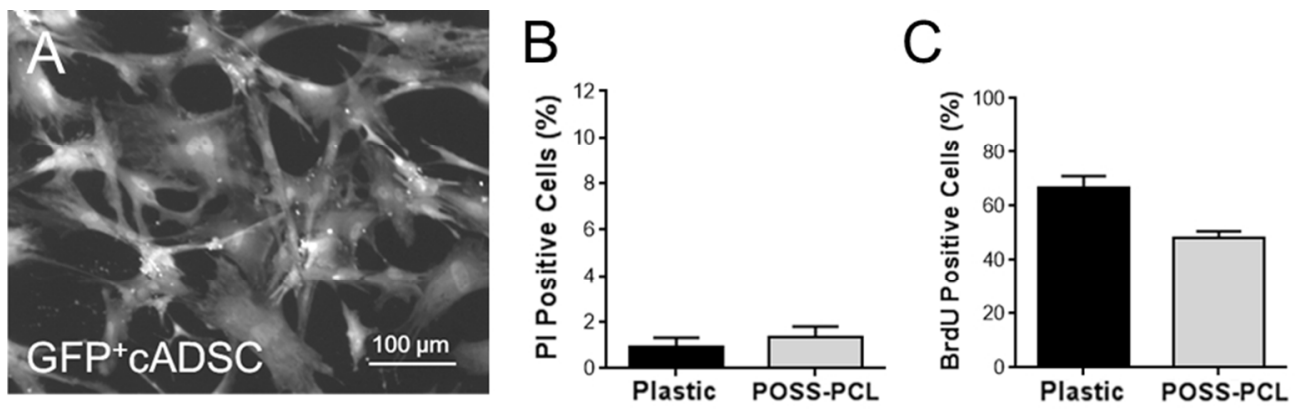

Figure 3. Viability and proliferation of ADSCs on monolayer POSS-PCL nanoscaffold. (A) GFP- expressing chick ADSCs seeded on monolayer nanoscaffold. (B) Percentage of dead cells detected by PI staining in pADSCs seeded onto either plastic or nanoscaffold. (C) Percentage of BrdU positive nuclei in pADSCs seeded onto either plastic or nanoscaffold. (B \& C) The experiments were performed on ADSCs isolated from three paediatric patients, Mean \pm SEM. $159 \times 49 \mathrm{~mm}(150 \times 150 \mathrm{DPI})$ 


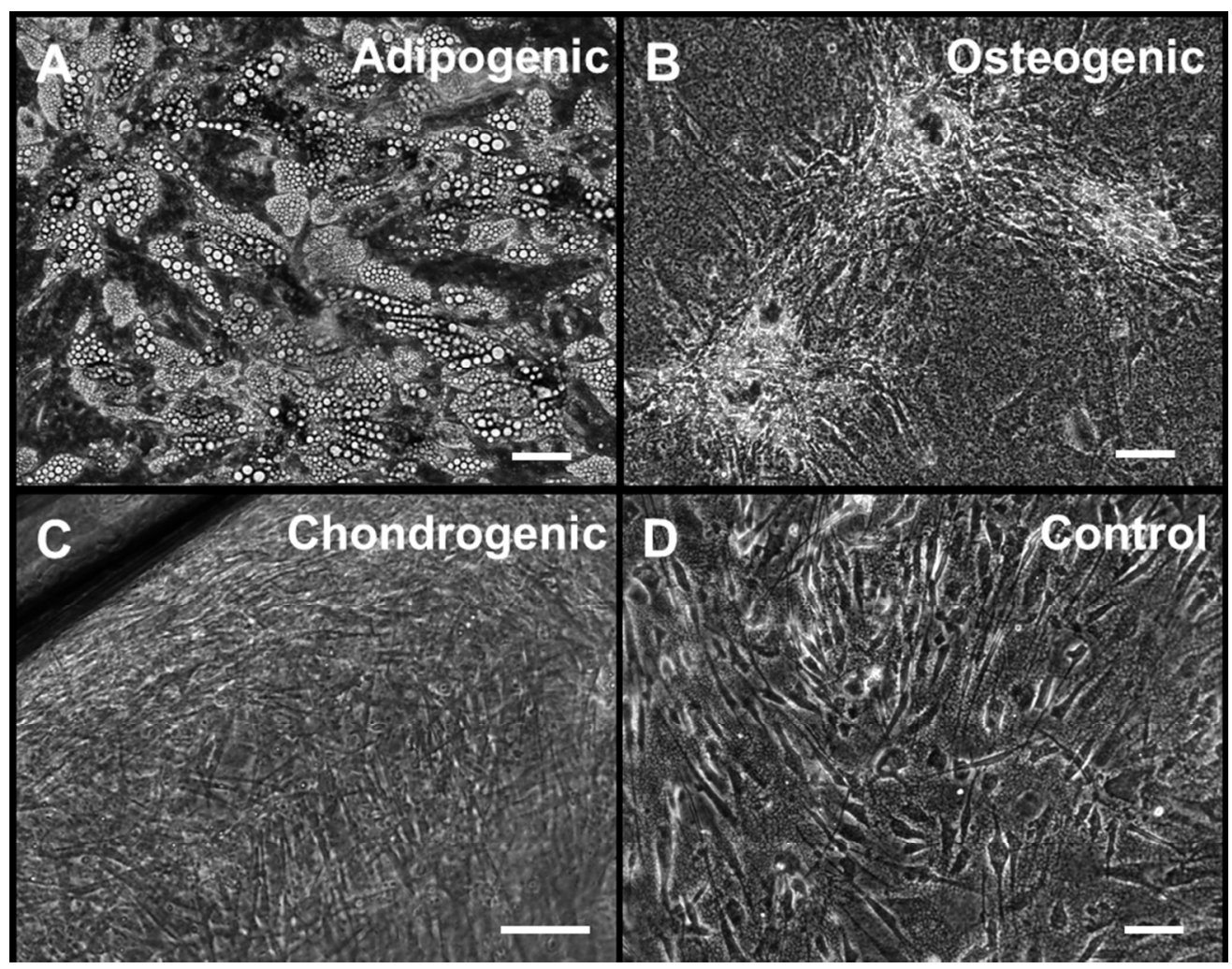

Figure 4. Differentiation potential of ADSCs on monolayer 2D POSS-PCL nanoscaffold. Representative brightfield images depicting morphology of pADSCs differentiated towards either adipogenic $(A)$, osteogenic $(B)$, or chondrogenic lineages (C), compared to pADSCs maintained under control conditions (D). (A-D) Scale bars equal to $100 \mu \mathrm{m}$. $164 \times 128 \mathrm{~mm}(150 \times 150 \mathrm{DPI})$ 

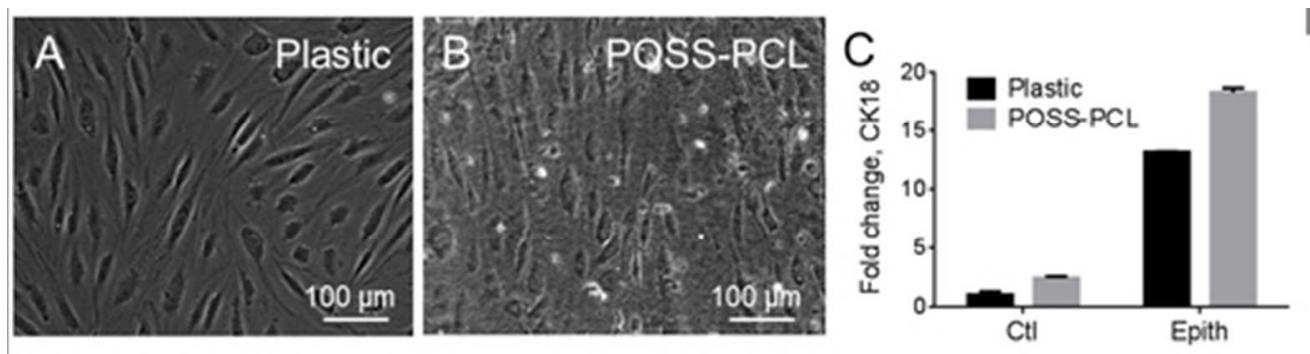

Figure 5. Epithelial differentiation of pADSCs on monolayer 2D POSS-PCL nanoscaffold. Representative brightfield images depicting the similar morphology of pADSCs differentiated towards the epithelial lineage seeded onto plastic (A) and POSS-PCL nanoscaffold (B). (C) CK-18 mRNA expression is upregulated in pADSCs seeded on both plastic and POSS-PCL. $180 \times 48 \mathrm{~mm}(72 \times 72 \mathrm{DPI})$ 

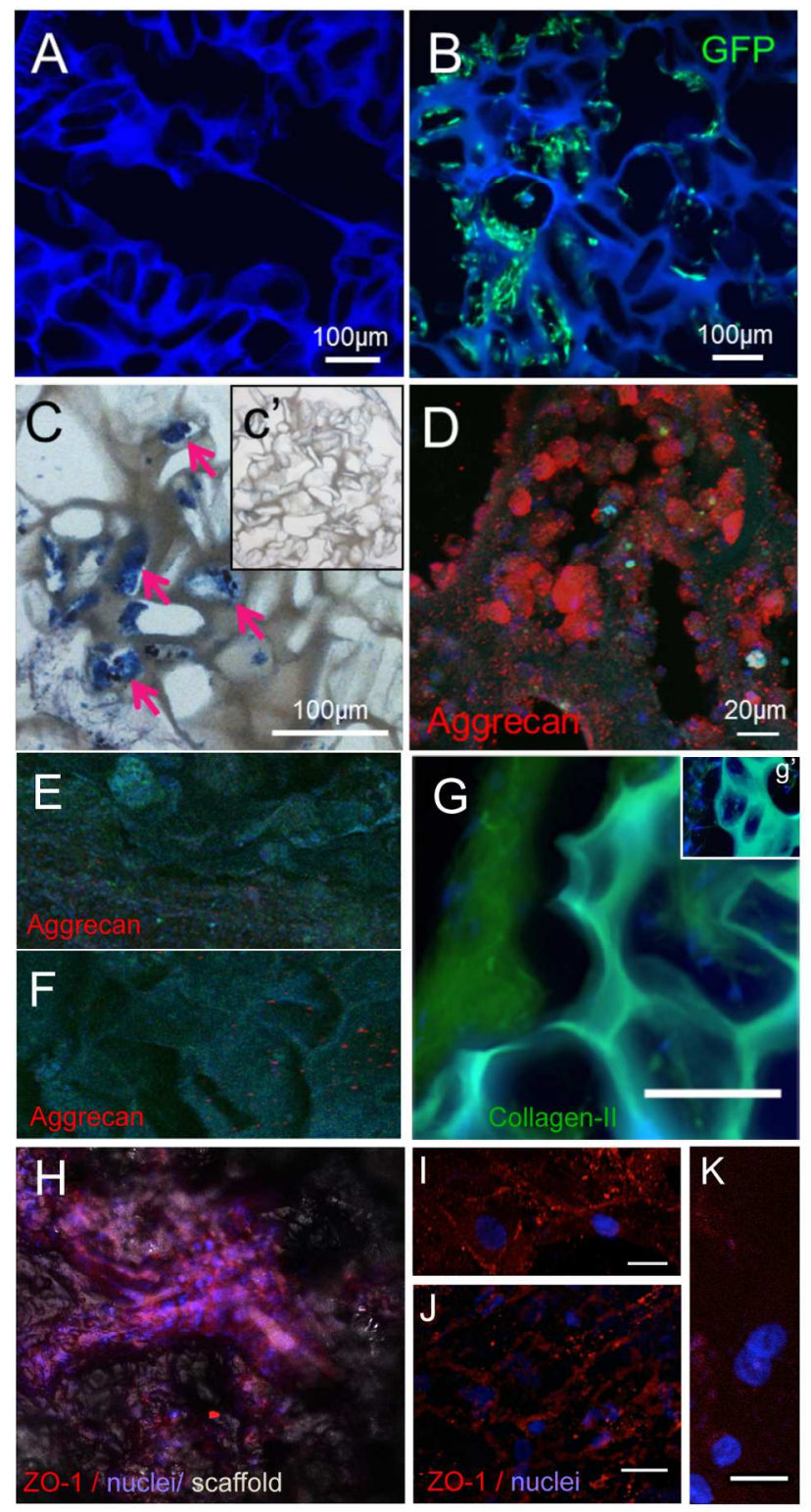

Figure 6. Migration and chondrogenic differentiation of GFP-expressing chick ADSC and pADSCs and epithelial differentiation of pADSCs in 3D POSS-PCL nanoscaffolds. Sections of unseeded and cellularized nanoscaffolds after 3 weeks in culture are shown in (A-F) whereas (G-J) show cells on the top surface of the nanoscaffold following epithelial differentiation induction. (A) Microstructure of unseeded nanoscaffold (blue), (B) GFP-expressing chick ADSC (green) seeded within the nanoscaffold (blue). (C) Alcian bluestained chick ADSC-nanoscaffold composites incubated in chondrogenic media; positive chondroid matrix is apparent (arrow); ( $C^{\prime}$ ) this is in contrast to composites incubated under control conditions. (D) The chondrogenic marker, aggrecan, is expressed in the GFP-expressing chick ADSC-nanoscaffold composites incubated in chondrogenic medium. (D-F) Aggrecan staining of CAM-grafted scaffolds seeded with: chondrogenically differentiated CADSC (E), undifferentiated CADSCS (E) and unseeded scaffolds $(F)$. Note that aggrecan deposition (red) is observed only upon chondrogenic differentiation. Images are at the same magnification. (G) Collagen-II staining following chondrogenic differentiation of pADSC seeded on POSSPCL; g': no primary antibody control. (H-J) Surface images of ZO-1(tight junction marker) staining of 
pADSCs following epithelial differentiation on 3D porous POSS-PCL. Low $(H)$ and high (I) magnification of epithelially differentiated pADSC; in (H) reflection is used to visualise the scaffold surface (grey). (I) Surface image of epithelially differentiated pADSC co-cultured with chondrogenic differentiated pADSC on POSS-PCL. (K) Control staining (secondary antibody only) of epithelially differentiated pADSC. Scale bars in $\mathrm{H}-\mathrm{K}=20 \mu \mathrm{m}$.

$105 \times 198 \mathrm{~mm}(300 \times 300$ DPI $)$ 


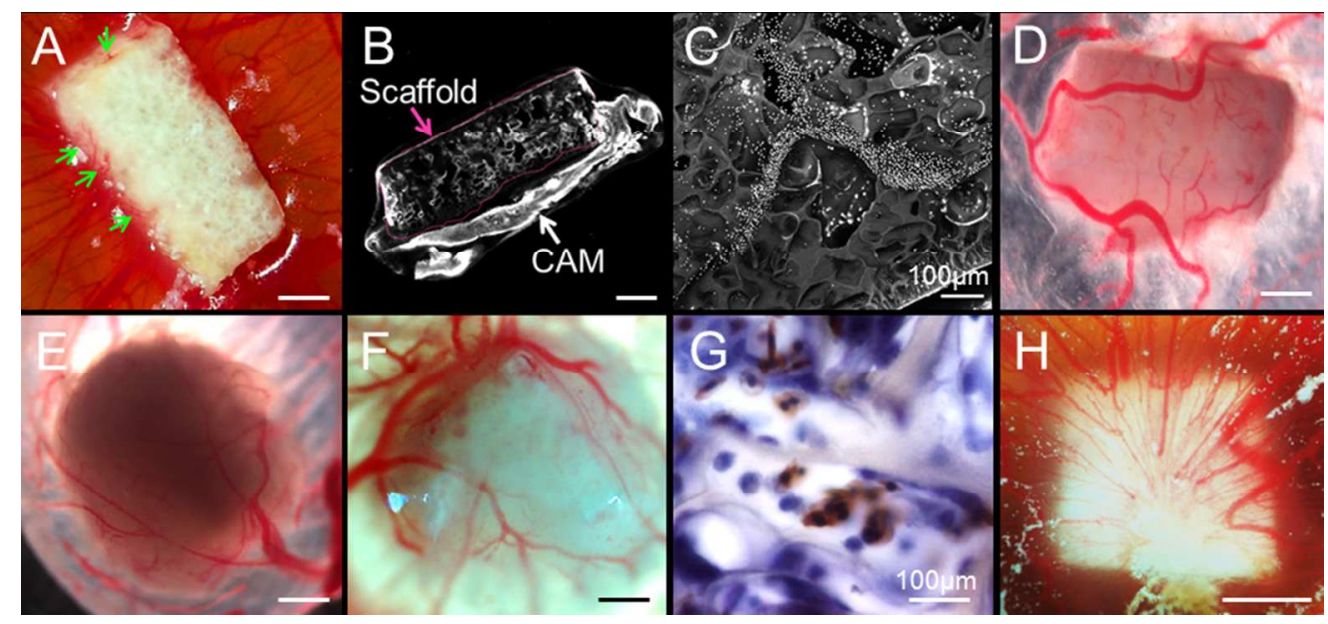

Figure 7. Biocompatibility of POSS-PCL nanoscaffolds. (A-C) In vivo characterization of unseeded POSS-PCL by chorioallantoic membrane (CAM) grafting: (A) Vascularization of unseeded POSS-PCL nanoscaffolds (arrows point to host vessels), (B) attachment of unseeded nanoscaffold to the CAM (scale bar $500 \mu \mathrm{m}$ ), (C) host cell infiltration of unseeded nanoscaffold as demonstrated by nuclei staining using Hoechst 33258. (D-

$\mathrm{H}$ ) In vivo characterization of ADSC-seeded nanoscaffold: (D) Vascularization of control chick ADSCnanoscaffold, and (E) chondrogenically-induced chick ADSC-nanoscaffold, $(F)$ vascularization of chondrogenically-induced pADSC-nanoscaffold. (G) Host cells labelled with an antibody specific for monocytes and macrophages are evident in the CAM-grafted pADSC-nanoscaffolds, brown expression is positive for mono/mac antibody; haematoxylin was used to counterstain nuclei blue. (H) Vascularisation of epithelium-lined chondrogenically-induced pADSC-nanoscaffold. (A-H) Scale bars equal to $500 \mu \mathrm{m}$, unless otherwise stated. $161 \times 74 \mathrm{~mm}(150 \times 150 \mathrm{DPI})$ 